\title{
ERRATUM
}

\section{Erratum to: An update on spinal cord injury research}

\author{
Yimin Zou* \\ Neurobiology Section, Biological Sciences Division, University of California San Diego, La Jolla, CA 92093 \\ *Guest Editor of the Special Issue, Associate Editor. E-mail: yzou@ucsd.edu \\ (c) Shanghai Institutes for Biological Sciences, CAS and Springer-Verlag Berlin Heidelberg 2013 \\ Erratum to: Neurosci Bull August 1, 2013, 29(4): 399-401 \\ DOI: $10.1007 / \mathrm{s} 12264-013-1366-3$ \\ The original version of this article unfortunately contained a few mistakes. The presentation of "local protein thesis" in \\ the 3rd line from bottom in right column on page 399 is incorrect. The corrected should be "local protein synthesis". \\ The word "Chondrotinase" in the 13th line from top in right column on page 400 is mis-spelled. The corrected should \\ be "Chondroitinase". The expression "A more severe and rapidly growing condition, traumatic brain injury, poses ever- \\ increasing challenges" in the 13th line of the last paragraph should be corrected to "A more severe and complex condition, \\ traumatic brain injury, is being increasingly recognized".
}

The original online version for this article can be found at: http://dx.doi.org/10.1007/s12264-013-1366-3. 